\title{
Equivalência terminológica gramatical entre o português e o italiano Paola Giustina Baccin
}

RESUMO: Apesar de semelhantes, as estruturas gramaticais do italiano e do português sāo diferentes. Portanto, a equivalência terminológica apresenta uma simplicidade aparente. Há termos que correspondem perfeitamente nas duas linguas; há outros, cujos significados coincidem apenas parcialmente e há conceitos inexistentes em um dos sistemas. A semelhança no nível do significante não significa que há equivalência no nivel do significado.

PALAVRAS-CHAVE: lexicologia bilíngüe; dicionário didático; língua italiana, rerminologia gramatical bilíngüe.

Italiano e Português: duas línguas neolatinas, com estruturas gramaticais semelhantes e terminologias correspondentes. A primeira vista, a equivalência terminológica de termos gramaticais não apresenta nenhum problema:

$$
\begin{aligned}
& \text { soggetto }=\text { sujeito } \\
& \text { verbo }=\text { verbo } \\
& \text { fonema }=\text { fonema } \\
& \text { pronome }=\text { pronome } \\
& \text { aggettivo }=\text { adjetivo }
\end{aligned}
$$

Uma breve reflexão comprova um princípio da correspondência lexical entre dois sistemas lingüísticos: semelhanças no nível do significante, não constituem uma correspondência ideal, absoluta no nível do significado.

A presente pesquisa surgiu do trabalho de tradução para o português da Grammatica Italiana di Base (Trifone e Palermo: 2000) e constitui a reflexāo inicial para 
a nossa pesquisa de pós-doutorado. Portanto, nosso objetivo nesse artigo é o de chamar a atenção dos profissionais na área do ensino do italiano para o cuidado no momento de estabelecer as equivalências terminológicas nas duas línguas. Esse problema surge, por exemplo, ao descrevermos, em português, os programas oficiais para os cursos de língua italiana ou quando os alunos precisam confrontar um determinado conceito em sua língua.

A Grammatica Italiana di Base é constituída por 14 capítulos que tratam dos seguintes assuntos: suoni e lettere; l'articolo; il nome; gli aggettivi qualificativi; gli aggettivi pronominali; i pronomi personali, relativi, allocutivi, doppi; il verbo; l'avverbio; la preposizione; la congiunzione; linteriezione; la frase semplice; la frase complessa e la formazione di parole.

Já no primeiro capítulo, observamos a dificuldade em estabelecer, para a terminologia da fonética e da fonologia, alguns termos equivalentes em português. Nesse campo, temos a contribuição do Professor Maurizio Babini que em seu livro Fonética, fonologia e ortoépia da língua italiana (São Paulo: Annablume, 2002) estabelece algumas correspondências, como por exemplo, para o termo approssimante. Na Grammatica Italiana di Base temos:

Le semiconsonanti sono definire approssimanti perché nel pronunciarle la lingua si avvicina agli organi fonatori senza però toccarli. Litaliano ha un'approssimante palatale /j/ e un'approssimante labiovelare /w/. (Trifone e Palermo: 2000, 3)

Para estabelecer os equivalentes, adotamos o seguinte procedimento:

1. procuramos os equivalentes nos dicionários da língua portuguesa (Aurélio e Houaiss);

2. verificamos nas gramáticas da língua portuguesa as definiçóes dos conceitos (Bechara: 2004 e Cunha e Cintra: 2001);

3. estabelecemos as equivalências dos sememas nas duas línguas;

4. em caso de dúvidas, consultamos outras obras da área de lingüística (v. bibliografia). 


\section{Portanto:}

Consoante aproximante. E. Ling. 1. Aquela em que a obstrução à passagem do ar é mínima, e não produz fricção. [Tb, se diz apenas aproximante.] (Aurélio)

Em Houaiss, Bechara (2004) e Cunha e Cintra (2001) não consta.

Uma vez que encontramos apenas uma definição nos documentos, e não pudemos estabelecer uma correspondência precisa entre os sememas nas duas línguas, consultamos outras fontes:

As semivogais e as semiconsoantes representam uma classe intermediária entre a das consoantes e a das vogais. A vibraçāo das cordas vocais encontra no conduto vocal menos obstáculos para as vogais, $\mathrm{e}$ mais para as consoantes. Dizemos que os articuladores tendem a se aproximar de uma zona de articulação consonântica, sem jamais aringi-la. Por essa razăo, os chamamos de aproximantes (approssimanti) ou glides. Conseqüentemente, utilizaremos o termo aproximante para englobar, às vezes, a classe das semiconsoantes e das semivogais. (Babini, 2002:31)

\section{Voltamos, então às obras de referência e confirmamos:}

glide. "[Ingl., 'deslize'.] S. m. E. Ling. 1. Som de transiçāo produzido enquanto os órgāos do trato vocal preparam a articulaçāo do som seguinte. 2. Semivogal." (Aurélio)

glide. Substantivo masculino. Rubrica: fonética. 1. som de transiçāo, nāo distintivo, produzido pela passagem dos órgáos fonadores e articuladores de uma posição para outra (p.ex., na fala carioca, entre uma vogal e uma chiante final é pronunciada a semivogal [i], que é um glide n[6i]s 'nós', p[ai]s 'paz' etc., por influência da chiante que, como o [i], é pronunciada perto do palato duro) 2 m.q. semivogal (Houaiss)

glide. Ao contrário dos fonemas líquidos, que são complexos (vocúlicos e consoânticos, simultaneamente), as semivogais e semiconsoantes săo fonemas neutros (nem vocálicos nem consoânticos). É o que os define como transigôes, passagens, glides. Por esse motivo, os fonemas neutros /w/ (dito "uau") e $/ \mathrm{j} /$ (dito, impropriamente, "iod"), aparecem nos ditongos e tritongos do português, junto a uma vogal que faz de centro da sflaba. (Lopes, 2000: 104)

A equivalência fica estabelecida da seguinte forma: approssimante = glide; (consoante) aproximante. 
Para os termos italianos semiconsonante e semivocale, a equivalência não é tão simples. Apesar de termos em português, no nível do significante, os correspondentes semivogal e semiconsoante, esses termos possuem, nas duas línguas, traços distintivos (sememas) diversos no nível do significado.

Le semivocali e le semiconsonanti si producono quando l'aria incontra un ostacolo più lieve di quello che dà luogo alle consonanti, ma più forte di quello che dà luogo alle vocali. (Trifone e Palermo: 2000:2)

O conectivo $e$ usado no parágrafo acima nos informa que se trata de dois termos distintos. Efetivamente, encontramos essa distinção nas gramáticas e nos dicionários italianos:

La $i$ e la $u$ dei dittonghi discendenti vengono chiamate semivocali per distinguerle dalle semiconsonanti $i / \mathrm{j} / \mathrm{e} u / \mathrm{w} /$ dei dittonghi ascendenti. Le prime, infatti, sono più vicine delle seconde al suono vocalico, e possono anzi considerarsi delle semplici varianti di posizione (v. 17.1.1) dei fonemi /i/ e /u/. (Dardano e Trifone: 1997: 677)

Em português, seguindo o procedimento que estabelecemos acima, encontramos para o termo semivogal as seguintes definiçōes:

[De semi- + vogal.] S. f. E. Ling. 1. Cada uma das vogais i e u quando, juntas a outra vogal, com ela formam uma sílaba. P. ex.: O i das palavras herói (he-rói) e Mário (Má-rio), e o u das palavras troféu (tro-féu) e quadro (qua-dro). 2. Som que, embora ocupe uma das margens da sílaba como uma consoante, é foneticamente semelhante a uma vogal; semiconsoante. [Sin. (ingl.), nesta acepç.: glide.]. (Aurélio)

Substantivo feminino. Rubrica: fonética, fonologia. Som da fala ou fonema que apresenta um grau de abertura do canal bucal menor do que o das vogais e maior do que o das consoantes, e que ocorre no início ou fim da sillaba, nunca no meio (as mais comuns sáo as semivogais altas fechadas $i$ e $u$, em quadro, pau, pai); glide, semiconsoante, vogal assilábica. (Houaiss)

Chamam-se semivogais as vogais $i \mathrm{e} u$ (orais ou nasais) quando assilábicas as quais acompanham a vogal numa mesma sílaba. Os encontros vocálicos dāo origem aos ditongos, tritongos e hiatos. Representamos as semivogais $i(e)$ por $/ \mathrm{y} / \mathrm{e} u(o)$ por $/ \mathrm{w} /$. (Bechara: 2004:66) 
Entre as vogais e as consoantes situam-se as semivogais, que sāo os fonemas /i/ e /u/ quando, juntos a uma vogal, com ela formam sillaba. Foneticamente estas vogais assilábicas transcrevem-se [j] e [w]. (Cunha e Cintra: 2001: 31)

Para o termo semiconsoante encontramos as seguintes informaçōes:

[De semi- + consoante.] S. f. E. Ling. 1. Semivogal (2). (Aurélio)

Substantivo feminino. Rubrica: fonética, fonologia. m.q. semivogal. (Houaiss)

Em Bechara (2004) e Cunha e Cintra (2001) nāo consta.

Em italiano, portanto, o termo semiconsonante é usado, principalmente, para indicar as semivogais quando estas precedem a vogal, formando um ditongo crescente (dittongo ascendente). $O$ termo semivocale denomina as semivogais $i$ e $u$ nos ditongos decrescentes (dittongo discendente). Em português, nāo ocorre essa distinçāo terminológica.

Seguindo o mesmo procedimento, observamos que essas variaçōes ocorrem em muitos termos gramaticais. $O$ termo adjetivo, por exemplo, aparentemente não apresenta nenhuma dificuldade de equivalência e corresponde ao português adjetivo.

1. aggettivo determinativo ou pronominale $\approx^{1}$ adjetivo determinativo ou pronominal;

2. aggettivo di relazione $\approx$ adjetivo de relaçāo;

3. aggettivo qualificativo $\approx$ adjetivo qualificativo.

Quando chegamos ao aggettivo pronominale verificamos que em português não há o termo adjetivo pronominal, por mais que o decalque pareça possível. Vejamos a definiçăo de aggettivo pronominale em Trifone e Palermo (2000: 80):

Gli aggettivi pronominali sono così chiamari perché, a differenza degli aggettivi qualificativi, possono avere anche valore di pronome: $i l$ mio (= aggetrivo) quaderno ì bianco, il tuo (= pronome)

1. Usamos o símbolo $\approx$ para indicar equivalência. 
è rosso; voglio questo (= aggettivo) libro, non quello (= pronome). Sono denominati anche aggettivi determinativi perché specificano il nome precisandone una caratteristica: il possessore, la posizione nello spazio, la quantità, la qualità, il numero.

\section{Em português esse conceito diz respeiro aos pronomes adjetivos:}

p. adjetivo. Rubrica: gramática. Pronome que modifica um substantivo (claro ou oculto), dando idéia de posse, de localizaçāo espacial ou temporal, de quantidade indeterminada, de indefiniçāo etc. (p.ex.: meu, teu, seu, este, esse, aguele, algum, nenhum, certos, vários, um etc.). (Houaiss)

Em português, temos pronomes substantivos e pronomes adjetivos:

Os pronomes substantivos aparecem isolados na frase, ao passo que os pronomes adjetivos se empregam sempre junto de um substantivo, com o qual concordam em gênero e número. Assim, nas frases: Lembranças a todos os teus. (E. da Cunha, OC, II, 646.) [e] Teus alhos sāo dois desejos. (R. Correia, PCP, 109.) a palavra teus é pronome substantivo, na primeira, e pronome adjetivo, na segunda. (Cunha, 2001:273)

\section{Bechara (1999:163) considera que}

o pronome pode aparecer em referência a substantivo claro ou oculto: $M e u$ livro é melhor que o teu. Meu e teu são pronomes porque dão idéia de posse em relação à pessoa do discurso [...]. Ambos os pronomes estão em referência ao substantivo livro que vem expresso no início, mas se cala no fim por estar perfeitamente claro ao falante e ouvinte. Esta referência a substantivo caracteriza a função adjetiva ou de adjunto de certos pronomes. Muitas vezes, sem que tenha vindo expresso anteriormenre, dispensa-se o substantivo, como em: Quero o meu e não o seu livro (onde ambos os pronomes possessivos sāo adjetivos).

Na tradução da gramática, optamos pela criação do decalque "adjetivo pronominal", indicado entre aspas e com a ressalva acima em nota, para facilitar ao leitor a relação com o termo em italiano.

Essas reflexóes nos motivaram a elaborar um glossário italiano-português, que contemple não apenas a tradução da terminologia gramatical, mas que, por meio de definiçóes e exemplos, esclareça ao professor de língua as diferenças entre os dois sistemas lingüísticos. 
ABSTRACT: Sebbene siano somiglianti, le strutture grammaticali dell' italiano e del portoghese sono differenti. Per questo, l'equivalenza terminologica presenta una semplicità solo apparente. Ci sono termini che corrispondono perfettamente nelle due lingue; altri il cui significato coincide solo parzialmente e ci sono concetti inesistenti in uno dei due sistemi. La somiglianza a livello di significante non significa che ci sia equivalenza a livello di significado.

PAROLE CHIAVE: lessicologia bilingue; dizionario didattico; lingua italiana, terminologia grammaticale bilingue.

\section{Bibliogralia}

BABINI, M. Fonética, fonologia e ortoépia da lingua italiana. São Paulo: Annablume, 2002.

BECHARA, E. Moderna gramática porruguesa. Rio de Janciro: Lucerna, 2004.

CUNHA, C. e CINTRA, L. Nova gramática do português contemporáneo. Rio de Janciro: Nova Fronteira, 2001.

DARDANO, M. e TRIFONE, P. La nuova grammatica della lingua italiana. Bologna: Zanichelli, 1997.

TRIFONE, P. e PALERMO, M. Grammatica italiana di base. Bologna: Zanichelli, 2000. 